\title{
O PROFESSOR E O ALUNO COMO AGENTES DO DESENVOLVIMENTO DA LEITURA
}

\author{
Debbie Mello Noble \\ Solange Mittmann
}

\begin{abstract}
RESUMO
Neste artigo, nos propomos a apresentar alguns apontamentos a respeito do desenvolvimento da leitura pelos alunos nas escolas. Partindo de uma concepção discursiva sobre a leitura, que leva em conta o jogo entre língua, condiçóes de sua produçáo e sujeito, consideramos que tanto professores como alunos têm papel atuante nesse desenvolvimento. Nesse sentido, defendemos uma prática docente que ofereça possibilidades de deslizamentos de sentidose de inserção dos alunos no jogo discursivo.
\end{abstract}

PALAVRAS-CHAVE: Ensino de leitura; prática docente; leitura e sentido.

“[...] ser leitor é a possibilidade de construção de um ser humano melhor, mais crítico, mais sensível; alguém capaz de se colocar no lugar do outro; alguém mais imaginativo e sonhador, alguém um pouco mais liberto dos tantos preconceitos que a sociedade vai impondo-nos a cada dia [...]” (RITER, 2009, p. 35).

\section{Introdução}

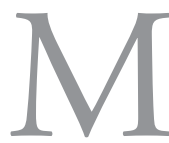

uito se tem falado sobre a crise da leitura e sobre o número cada vez menor de crianças e adolescentes com o hábito e o gosto por essa prática. No entanto, dizer que o jovem que se encontra hoje nos bancos escolares não sabe ler ou não tem interesse por práticas de 
leitura é aceitar o discurso do senso comum e não se propor a refletir acerca desta questão.

Assim, neste artigo, procuramos refletir para além do que se tem dito no senso comum sobre a chamada crise da leitura, pois buscamos compreender o que se tem feito e o que se pode vir a fazer no que concerne ao papel do professor de educaçáo básica no desenvolvimento da proficiência de leitura de seus alunos.

Antes de apresentar uma discussão sobre a prática docente a respeito da leitura, adiantamo-nos em precisar alguns fundamentos teóricos sobre língua e sujeito que sustentam nossa concepção sobre a leitura.

\section{Alguns pressupostos sobre língua e sujeito}

Compartilhamos com Cazarin (2006, p. 2) a posição de que "a partir de como a noção de língua é concebida, a direção que damos às práticas de leitura e de escrita pode ser uma ou outra (...) essa noção implica uma direçáo metodológica de nosso fazer pedagógico”. Então, comecemos pela língua.

Partimos de uma perspectiva discursiva sobre a noção de língua, considerando a historicidade, isto é, o intrincamento - como um nó que não se desfaz - entre língua e história. Tomar esse intrincamento como pressuposto traz algumas consequências: consideramos que a autonomia da língua é relativa, que a história não é apenas um contexto eventual e, sim, que se trata das condições de produção do discurso. Isso significa dizer que a relação com a história não apenas influencia a língua, mas a atravessa de forma inevitável.

É desse intrincamento que temos o discurso. Como afirma Indursky (1998, p. 12), é necessário considerar as condiçóes de produção de um funcionamento linguístico que "deixa de ser apenas linguístico para tornar-se também discursivo; vale dizer, é preciso relacioná-lo à exterioridade, à conjuntura histórico-social em que foi produzido, ao lugar social em que seu sujeito está inscrito e à rede de formulaçóes já existente”.

O discurso tem, portanto, uma dupla materialidade: a materialidade linguística, que é a base da qual partimos para o ato da leitura, e a materialidade histórica, que intervém acionando sentidos possíveis através dos gestos de leitura. Note-se aqui a distinção entre ato de leitura, que é da ordem da empiria, ou seja, quando o sujeito se depara como o objeto a ler, e gestos de leitura, que 
são os movimentos que levam às possíveis interpretações sobre o objeto. E, quando falamos em possíveis interpretaçôes, estamos nos reportando a uma concepção de língua que permite deslizamentos de sentidos. Não trabalhamos com uma língua fechada em si, regular, maciça, mas com uma língua que tem em si espaços, furos, silêncios, por onde o sujeito pode entrar, significar e significar-se.

E se é pela língua - como base material do discurso - que o sujeito se significa como sujeito de discurso, não cabe falar em uso da língua pelo sujeito. Negamos, portanto, a concepção de língua como instrumento de comunicação, que tornaria possível - através da leitura - fazer chegar sentidos pretendidos, codificados pelo autor e decodificados pelo leitor. O sujeito, na concepção discursiva que defendemos, não é anterior à língua, nem ao discurso - como um autor que se buscaria recuperar de um passado de escrita através de uma leitura no presente.

Desviamos do empirismo da mera interlocução e trabalhamos o sujeito do discurso. E abordar o sujeito do discurso também não significa nos mantermos na (inter)subjetividade enunciativa, pois trabalhamos com uma concepção de sujeito que considera o funcionamento da ideologia e do inconsciente: "Isso supóe que o sujeito deixe de ser considerado como o eu-consciência mestre de sentido e seja reconhecido como assujeitado ao discurso: da noçáo de subjetividade ou intersubjetividade passamos assim à de assujeitamento" (PÊCHEUX, 2012, p. 156).

Por isso, consideramos que o discurso forma uma espécie de nó em que funcionam a língua como base material, a história como condiçôes de produção e o sujeito como efeito. Por isso, discurso não é mensagem, não é comunicação, é efeito de sentidos. E é com base nessa concepção de discurso que tomamos a leitura como objeto de reflexão neste artigo.

\section{Concepções de leitura}

Sabemos que os suportes de leitura vêm se transformando ao longo dos tempos juntamente com os modos de ler, fato que presenciamos a cada dia, especialmente com a evolução cada vez mais rápida das tecnologias. Historicamente, temos visto que a mudança no suporte influencia e modifica os modos de leitura, desde a passagem do rolo para o códice medieval, e deste para o 
livro impresso, que transformaram os gestos corporais em relação ao ato de ler (SPALDING, 2011). Com isso, desfazemos mais algumas evidências relacionadas à leitura: não há somente um modo correto de ler, seja em relação ao ato de ler ou ao gesto de leitura, pois, assim como não há somente um suporte de leitura, não há um sentido único para cada objeto a ser lido.

Por esse motivo, podemos dizer que o gesto de leitura não diz respeito somente à leitura da palavra escrita. Sabemos que há uma série de situações com as quais nos deparamos em nosso cotidiano que exigem leitura: a leitura de uma pessoa, de uma $\mathrm{m}$ de uma imagem, por exemplo. Esses modos de ler nos dizem que a leitura vai além da decodificação dos símbolos da escrita. Assim, quando estamos diante de um texto escrito, é preciso interpretá-lo tal como fazemos com os outros modos de leitura, indo além dos sentidos evidentes.

Dessa forma, baseadas principalmente no que diz Orlandi (2012) e na perspectiva discursiva assumida por ela, é que estabelecemos a nossa concepção de leitura como parte de um processo de instauração dos sentidos possíveis, não aceitando o texto como um produto pronto, do qual se extrairiam os sentidos. O gesto de leitura é um gesto de interpretação simbólica, cujos sentidos não estão já dados, mas são construídos pelo sujeito-leitor, enquanto este também se constitui.

Nesse sentido, Cazarin elucida que o gesto de ler se constitui "em uma prática social que mobiliza o interdiscurso, conduzindo o leitor, enquanto sujeito histórico, a inscrever-se em uma disputa de interpretaçóes" (2006, p. 2). Essas interpretaçóes vão depender do lugar de onde o sujeito as produz, uma vez que os sentidos se dáo de acordo com a posição-sujeito em que se inscreve aquele que lê, e com o modo como a memória discursiva intervém quando se produz um gesto de interpretação.

É dessa forma que pensamos a leitura escolar, que tem sido tomada frequentemente como decodificação, "adivinhação" dos sentidos corretos, ocupando um plano secundário a ela reservado. Isso porque o aluno não é estimulado a ir além em suas interpretaçóes; ele é, muitas vezes, interditado de interpretar.

Pensando sobre o lugar social de onde os sujeitos produzem suas interpretaçóes, lembramos da relação de dominância do professor em relação ao aluno no que diz respeito ao direito de produzir gestos de interpretação. Nesse sentido, o sujeito, conforme Cazarin (2006, p. 7), "ao produzir leituras, o 
faz determinado pelo imaginário do 'lugar social' em que se inscreve. É esse lugar que o lança em um processo histórico de interpretação e de disputa na produção de sentidos". Assim, muitas vezes, o sujeito aluno se exime de lançar um gesto interpretativo sobre determinado texto, pois acredita haver apenas uma resposta correta, já que, do lugar social que ocupa, não se acredita capaz de realizar suas próprias leituras.

Da mesma forma, os momentos reservados à leitura na escola ou são tomados como "tempo livre", ou servem a uma atividade avaliativa posterior, ou seja, não possuem fim em si mesmos, não levam o aluno a conhecer a fruição e o prazer de ler.

No que diz respeito ao desenvolvimento leitor de nossos alunos, consideramos que é possível aprimorá-lo cada vez mais se lembrarmos que "o sentido sempre pode ser outro”, pois, uma vez que não há sentido único e pré-estabelecido como correto para um texto, não se espera do aluno que desvende ou decodifique. É o que afirma Orlandi: "O ensino da leitura pode, dependendo das circunstâncias pedagógicas, colocar a ênfase tanto na multiplicidade de sentidos quanto no sentido dominante" (2012, p. 61).

$\mathrm{Na}$ prática, isso tem a ver com não levar um texto para sala de aula como pretexto para uma atividade avaliativa, em que há previamente uma resposta determinada como correta; mas sim preocupar-se com o que pode levar o aluno à fruição, ao prazer de ler, por meio do entendimento de que há múltiplos sentidos possíveis para o que se está lendo, e não um sentido único, e também de que cada aluno precisa partir de sua própria "história de leituras", como defende Orlandi.

Em relação ao papel do professor, Riter (2009) argumenta que o professor que busca formar o leitor literário na escola possui três importantes funçóes. A primeira diz respeito a tornar-se um contador de histórias, necessitando envolver o leitor na história, a fim de aproximar o texto de seu aluno, propiciando a vivência literária a partir da escuta. Uma segunda função do professor é ser um guia do estudante na biblioteca, sugerindo livros para seus alunos, orientando-os na leitura, realizando eventos atrativos com relação ao livro, como feiras do livro, saraus literários, horas do conto, etc. O professor precisa ser um incentivador de leitura, buscando fazer o aluno apaixonar-se pela leitura e perceber que o livro esconde uma beleza através de histórias: "é necessário que ele seja um ser apaixonado pela leitura, alguém que tenha 
consciência de que ler faz a diferença” (Riter, 2009, p. 73). O autor esclarece, ainda, que o professor precisa mediar a leitura em sala de aula, uma vez que o texto literário não é mero objeto a ser decifrado pelo aluno, mas uma obra que precisa ser vivenciada.

Assim, como vimos, o professor tem um papel importante em relação ao estímulo e à mediação do aluno com a leitura, buscando fazê-lo compreender que não há um sentido único nem correto para cada texto.

\section{Algumas propostas}

Para ampliarmos nossa perspectiva sobre o tema, podemos traçar um breve comparativo entre duas formas como as obras literárias podem ser oferecidas aos alunos: como mero cumprimento de tarefa, com a obrigatoriedade de escrever fichas de leitura vinculadas ao conteúdo a ser apreendido e desconectadas das questóes do próprio leitor; ou a partir do despertar de um desejo do aluno, ou seja, a partir da sedução para a leitura e, ainda, com um trabalho de pós-leitura que continue envolvendo o aluno e suas questôes, fazendo com que a obra passe a fazer parte da vida do leitor.

Não se trata aqui de dizer ao professor que "venda" livros aos seus alunos, e tampouco de tratar o aluno como consumidor e o ensino como mercadoria, muito pelo contrário. Trata-se de tornar os livros e a leitura tấo atrativos e envolventes, nesse trabalho pela formação de um leitor apaixonado, que continuará sendo leitor curioso depois de passar pela escola.

Nesse sentido, Orlandi (2012, p. 61) traz uma sugestão apropriada: “os professores proporem uma organização curricular que fosse capaz de provocar o aluno a trabalhar em sua própria história de leitura”. Ou seja, fazer com que o currículo tenha espaço para as histórias de leitura dos alunos, aquelas leituras outras que já chegam com os alunos à escola, ou, como diz a célebre frase de Paulo Freire, é preciso lembrar que "a leitura de mundo precede a leitura da palavra”. Neste caminho está também a proposta de Volker (2014), a qual trabalha com a utilização dos best-sellers em sala de aula, valorizando, assim, a habilidade dos alunos de também proporem suas leituras, e abrir espaço para um futuro desejo de conhecer o cânone.

Nesse ponto, a universidade tem papel crucial na formação de professores para que não considerem somente um tipo de leitura na escola. É preciso, 
em primeiro lugar, instigar os novos professores da educação básica a pensarem além do tradicional desde o início de sua formação e de sua prática. Isso só é possível se os levarmos a compreender que alunos irão encontrar - alunos esses que, nos dias atuais, comunicam-se e participam de diversos eventos de letramento - e quais discursos se organizam em torno das leituras realizadas.

Comumente, as atividades de leitura e produção textual tomam como base textos de autores consagrados, que servem como exemplo de bem escrever, ou seja, autores que sabem usar a gramática normativa (embora muitos confessem contar com os revisores das editoras), que sabem trabalhar esteticamente com a palavra, que desenvolvem adequadamente os argumentos de determinados gêneros textuais ou discursivos. Nossa proposta neste artigo segue uma direção paralela: propomos que se trabalhe também com textos produzidos em condiçóes de exclusão e invisibilidade. Nesse sentido, apresentamos uma proposta de trabalho que parte da leitura de textos do jornal Boca de Rua, que é produzido por um grupo de pessoas em situação de rua na cidade de Porto Alegre/RS. Os textos são elaborados em oficinas semanais desde 2001, e seu processo de produção pode ser visto no web documentário Boca de Rua - Vozes de uma gente invisivel, de 2013, com roteiro e direção de Marcelo Andrighetti ${ }^{1}$.

Em certo trecho do documentário de dez minutos, uma legenda diz que no jornal Boca de Rua "os integrantes aprendem a ler, a escrever e a lutar contra a invisibilidade”. Para nós, esse é um exemplar possível de ser levado para a sala de aula, pois toma a leitura e a escrita como gestos de identificação dos sujeitos envolvidos e de transformação das condições de existência. Assistir ao vídeo e discutir conjuntamente sobre seu próprio olhar a respeito da cidade, da urbanidade, dos sujeitos que ali (con)vivem podem possibilitar aos alunos um olhar para si e para o outro, uma (re)avaliação das condiçóes de existência e, finalmente, uma reflexão sobre os gestos (próprios e dos outros) de interpretação lançados sobre o mundo, os sujeitos, a informação, a escrita, a leitura...

$\mathrm{Na}$ edição do primeiro trimestre de 2010, foi publicada uma matéria que versava sobre os documentos que todo cidadão deve(ria) ter - como a carteira de identidade, que é o principal deles -, as dificuldades para obtenção dos documentos e a falta de acesso a certos serviços sociais ou governamentais

1 O referido documentário pode ser encontrado em: www.youtube.com/watch?v= 5TtoMSiRn0w. 
em virtude da ausência de tais documentos. Produzida sob a perspectiva de sujeitos em situação de rua, a matéria mostra que não portar determinados documentos leva a não ter seus direitos de cidadão respeitados, ou mesmo a não ser considerado um sujeito cidadão com direitos.

Recortamos desta matéria os dois textos a seguir:

\section{"João Alguém"}

Para quem mora na rua é difícil ter documentos. A pessoa não tem estímulo: para que carteira de trabalho, se não tem trabalho? Também não sabe direito como encaminhar e falta um telefone para se informar ao certo. Porque cada documento - carteira de identidade, CPF, título de eleitor, carteira de trabalho - é feito em um lugar diferente. Também falta dinheiro para tirar as fotos e pagar as taxas. Só que mesmo os moradores de rua precisam de documentos. Sem o atestado de residência, por exemplo, quase todos os postos de saúde se negam a atender. Fica impossível votar, pegar receita ou preservativo no postinho, abrir conta bancária. A pessoa fica de fora na sociedade. Além de não ter casa, perde seus direitos, vira um João Ninguém. Isso não é justo. Todo mundo é um João Alguém.

"Identidade sem papel"

Quando uma pessoa perde a carteira de identidade é ruim. Mas ela não perde a identidade. Porque identidade é o que a própria pessoa é e não um documento, um pedaço de papel. Ela pode não ter nenhum documento e mesmo assim vai ter identidade. A identidade é feita de carne, osso e pensamento. Cada um tem a sua própria identidade, que são as características da pessoa. Uns são simpáticos, outros não; uns são bons, outros sáo maus ou mais ou menos; uns pensam muito, outros pensam pouco. Tem gente que gosta de Carnaval, de doce, de novela, de jornal e de filme, ou só de algumas destas coisas, ou de nenhuma destas coisas. Tem pessoas que vão para faculdade $\mathrm{e}$ outras que nem aprendem a ler. Mesmo assim, esta pessoa vai ser importante porque vai aprender o que se passa no mundo. 
Existem os que são criados pelos pais e os que são criados por outras pessoas. A educação é importante para fazer as pessoas diferentes e melhores. Pela educação se aprende as coisas mais boas da vida. E não é só a educação do colégio, mas também a dos pais, a dos irmãos mais velhos, dos tios e de quem conhece as coisas. Mesmo quem não sabe escrever é importante, porque essa pessoa sabe muito do que se passa no mundo e pode ensinar para os menores.

O primeiro texto questiona a burocracia, defendendo que antes do documento há questôes mais urgentes, prioritárias, como quando pergunta: para que carteira de trabalho, se não tem trabalho? Após uma relação de documentos exigidos e das dificuldades em obtê-los, mostra o absurdo de se exigir atestado de residência a quem não tem residência. Mas o absurdo maior fica por conta de não ter contemplados seus direitos de cidadáo e de ser tomado, definido, identificado pela negação: como um ninguém. Reivindica, então, o direito de ser identificado como alguém, por fazer parte do grupo de sujeitos da cidade. E é esse ser alguém o mote do segundo texto, que joga com a palavra identidade, ora apontando para o documento de identidade, ora para a pessoa que se é independentemente do porte do documento. Para considerarmos esse jogo com a palavra, recorremos a Pêcheux (2012, p. 158): "não há, de início, uma estrutura sêmica do objeto, e em seguida aplicaçóes variadas dessa estrutura nesta ou naquela situação". Não se trata de situação, nem de uso da palavra. Trata-se, como se pode observar principalmente no segundo texto, de disputa pelo sentido. Entre a identidade da burocracia e a identidade do cotidiano social do sujeito, entre o aprendizado na escola e o aprendizado na vida fora da escola, o sujeito se constitui pela relação com os outros (os sujeitos sociais com quem convive) e o Outro (a ideologia) que o interpela como sujeito. Tal reflexão pode colocar em questionamento a constituição de nossa própria identidade, nossa relação com o outro e o Outro.

Esses são alguns aspectos de uma das muitas (mas não quaisquer, fique claro) leituras possíveis dos dois textos. E se considerarmos que não apenas o sujeito social empírico se constitui pela relação com o outro e o Outro, mas também o sujeito do discurso, que se apresenta como posiçóes em conflito no jogo discursivo de dizer e dizer-se para si e para o outro, teremos aí uma bela 
possibilidade de articulação entre leitura, estudo de funcionamentos discursivos de elementos da língua e, finalmente, produção de novos discursos através da escrita de novos textos sobre o tema.

\section{Considerações finais}

Como afirmamos em outro texto (MITTMANN, 2007), o processo discursivo - aqui entendido como processo de acionamento de sentidos tanto na leitura como na escrita - pode fazer falar tanto o dito, como o não dito, ou, ainda, o dito em outro lugar e que vem ressoar de modo vertical sobre a horizontalidade do fio do discurso. Um trabalho de leitura em sala de aula deve envolver tanto o que pode ser dito de modo parafrástico a partir das mesmas condiçóes de produção, como o que pode ou não pode ser dito de modo polissêmico sob outras condiçóes de produção. E é exatamente esse jogo entre paráfrase e polissemia - o mesmo e o diferente (ou até o divergente) - que se apresenta nos dois textos do jornal e que pode ser explorado em sala de aula para que os alunos possam identificar os dois processos tanto na leitura como na sua própria escrita.

Enfim, ler, escrever, ensinar em sala de aula em grande parte depende de tomada de posição do professor diante dos alunos com quem convive. E se sua posição for pela formação de leitores investigativos, críticos, dispostos a atuar em sociedade como transformadores das próprias condições de existência, é fundamental instrumentalizá-los, aguçar seu olhar e sua curiosidade sobre o texto, a língua, os processos discursivos, a interpretação, os próprios atos e gestos de leitura e escrita.

\section{Referências}

BOCA DE RUA. Porto Alegre, ano VIII, n. 35, janeiro, fevereiro e março de 2010.

CAZARIN, Ercília Ana. A leitura: uma prática discursiva. Revista Linguagem em (Dis)curso. v.6, n.2, maio/ago. 2006. Disponível em: www.portaldeperiodicos.unisul.br/index.php/Linguagem_Discurso/, 20/10/2015.

INDURSKY, Freda. A Análise do Discurso e sua inserção no campo das ciências da linguagem. Cadernos do IL, Porto Alegre, n.20, p. 7-21, 1998. 
MITTMANN, Solange. Formação do leitor: o que o ensino de gramática tem a ver com isso? In: CAZARIN, Ercília Ana; RASIA, Gesualda. (Org.). Ensino e aprendizagem de línguas: Língua Portuguesa. Ijuí, 2007, p. 81-105.

ORLANDI, Eni P. Discurso e leitura. São Paulo: Cortez, 2012.

PÊCHEUX, Michel. Metáfora e interdiscurso. In: PÊCHEUX, Michel. Análise de Discurso. Campinas: Pontes, 2012.

RITER, Caio. A formação do leitor literário em casa e na escola. São Paulo: Biruta, 2009.

SPALDING, Marcelo. História da Leitura. Digestivo cultural, São Paulo, 2011.

\title{
TEACHER AND STUDENT AS AGENTS IN THE READING DEVELOPMENT
}

\begin{abstract}
In this article we intend to present some notes in terms of the development of the reading process by the students in schools. Based on a discursive conception of the reading process, which takes into account the game among language, its conditions of production and subject, we consider that not only students but also teachers play an active role in this development. In this sense, we defend a teaching practice which offers possibilities of slipping of meanings and therefore the insertion of students in the discursive game.
\end{abstract}

KEYWORDS: reading teaching; teaching practice; reading and meaning.

Recebido em: 31/10/2015

Aprovado em: 23/01/2016 